Original Article

\title{
SKIN CANCER SCREENING CAMPAIGN IN THE GERMAN SPEAKING COMMUNITY OF BELGIUM
}

\author{
A.F. Nikkels ${ }^{1,2}$, N. Nikkels-Tassoudji ${ }^{1}$, E. Jerusalem-Noury ${ }^{3}$, \\ H. Sandman-Lobusch ${ }^{3}$, G. Sproten ${ }^{4}$, G. Zeimers ${ }^{5}$, \\ J. Schroeder ${ }^{6}$, G.E. Piérard ${ }^{7}$
}

\begin{abstract}
The incidence of primary malignant melanoma (MM) and skin carcinomas, including basal cell carcinoma (BCC) and squamous cell carcinoma (SCC), is progressively raising. As long as their diagnosis and therapeutic managements are initiated early, their prognosis remains favorable. This underlines the importance of early recognition of skin cancers. Furthermore, it has been demonstrated that skin cancer screening programs are efficacious in increasing the population awareness of the early signs of skin cancer and of the dangers of UV - exposure.

\footnotetext{
${ }^{1}$ Dermatologist, St Joseph Clinic, St Vith,

${ }^{2}$ Research associate,

${ }^{7}$ Head of department,

Service de Dermatopathologie,

CHU du Sart Tilman,

${ }^{3}$ Dermatologists, Eupen,

${ }^{4}$ Dermatologist, St Nikolaus Hospital, Eupen,

${ }^{5}$ Assistant,

${ }^{6}$ Head of department, Family, Health, and Social Affairs,

Address for correspondence:

Dr A.F. Nikkels

Service de Dermatopathologie

CHU du Sart Tilman 4000 Liège

Tel: 04/3662499

Fax: 04/3662976

E-mail: af.nikkels@chu.ulg.ac.be
} Ministry of the German speaking Community of Belgium.
\end{abstract}

A skin cancer screening campaign was organised by dermatologists of the German-speaking Community of Belgium in cooperation with the department of Family, Health, and Social Affairs of the Regional Ministry of the German-speaking Community of Belgium. In order to increase the screening selectivity, two risk populations were targeted; patients presenting 30 or more moles, and patients over 50 years of age presenting recent skin changes of the head and neck area. A media campaign using radio, television and daily press was started to increase the population awareness of the dangers of UV exposure and of the early signs of skin cancer. During 2 screening days, three-hour sessions were organised in 2 health centers located in Eupen and St Vith. A total of 148 patients were examined.

A total of 124/148 patients met the selection criteria predefined during the media announcement. The simultaneous presence of 4 dermatologists during the screening sessions allowed a second opinion for warning lesions. Four BBCs as well as 23 patients pesenting dysplastic nevi were clinically diagnosed. During the 2 months following the screening campaign $5 \mathrm{MMs}$ were identified by the same dermatologists in their routine practice.

In conclusion, this skin cancer screening campaign led to the diagnosis of 4 carcinomas. The campaign furthermore increased the patient awareness, permitting the diagnosis of $5 \mathrm{MMs}$ during the 2 following months. This figure represents about $30 \%$ of all MMs diagnosed yearly in this region of Belgium. 


\section{INTRODUCTION}

The prevalence of skin carcinomas, including basal cell carcinoma (BCC) and squamous cell carcinoma (SCC), and of malignant melanoma (MM) is on the rise over the past decades (1-11). Even if BCCs present almost no risk of dissemination, serious tumor- and treatment-related morbidity may be associated with large infiltrating lesions (12-14). Although the risk of metastasis is low for small size SCC, it may lead to serious morbidity $(6,12,15-18)$. The danger of MM is linked to the development of metastases often associated with a very poor prognosis. The risk of metastasis and the prognosis of MM are strongly related to the primary tumor thickness and to the sentinel lymph node invasion $(19,20)$.

Various types of skin cancer screening campaigns (1) have been organised at a large scale in the USA (21), Australia (22-24), and in Europe (25). These campaigns have proven to be useful by several aspects. They encouraged self-examination $(4,26)$, provided educational messages about sun protection, and helped in early detection of MM and skin carcinomas during and after the campaigns (27-30). Patient education and self-examination increases the impact of office-based screening and mass screening programs $(27,31,32)$. Even if the number of new cases of skin cancer disclosed during these campaigns may appear limited, a main benefit is the increase of new cases diagnosed in the months following the campaigns (25).

Visual examination by dermatologists has been proven effective for skin cancer screening purposes (1). Dermoscopy represents a valuable tool to complement visual examination $(33,34)$. In the recent years, retrospective data show 10-15 new cases of MM in the about 70.000 inhabitants of the German-speaking Community of Belgium (data gathered over 8 years from the laboratory for pathology, Sankt Nikolaus Hospital Eupen, and the laboratory for dermatopathology of the Liège University).

Due to its particular linguistic status, the former Belgian Melanoma Monday and the current Euromelanoma campaigns were never successfully organised in the German-speaking Community of Belgium. The department of Family, Health, and Social Affairs of the Ministry of the German-speaking community and the dermatologists practicing in this region organised a targeted skin cancer screening campaign in 2003. It was previously reported that screening focused on MM increases the detection of lesions suggestive of MM and dysplastic nevi, but decreased the proportions of disclosed BCC, SCC and actinic keratoses (35). As our goal was to screen all skin cancers, the media campaign provided information about each major type of skin cancer. Two weeks before the screening days, a media campaign involving the radio, television and daily press was launched. It dealt with skin cancers, sun protection, how to decrease skin cancer risk and how to recognize the early signs of skin cancers. It is acknowledged that screening never proved to help in reducing the MM mortality rates $(28,30,36-39)$. Screening should rather target risk groups (40). Therefore, two risk populations were solicited, namely patients presenting 30 moles or more, and patients over the age of 50 years presenting recent skin changes in the head and neck area.. Skin changes were defined as skin lesions that had appeared recently, or lesions that had recently begun to scale, to bleed and/or to crust. Patients who met the selection criteria were invited to present themselves at the screening centers. A centralised appointment office was operative using a single phone call number where patients were orally screened and controlled on the selection criteria. The patients were then dispatched to one of the two screening centres located in Eupen and St Vith. During two screening days, the patients were examined randomly by one of the 4 dermatologists who were simultaneously devoted to skin cancer screening for 3 hours. Furthermore, patients were provided with an information sheet about skin cancers, sun avoidance, and dangers of UV-exposure.

\section{MATERIALS AND METHODS}

The following data were recorded during the screening campaign: age, gender, occupation (indoor or outdoor), phototype (I to V), sunburns during infancy $(<12$ years) (frequent or rare), current and past use of tanning UV-delivering devices $(1,5,10$, or more than 10 sessions per year), patient meeting the selection criteria (yes or no), number of diagnostic opinions regarding the present skin tumors, and the clinical and dermoscopy diagnosis of the screened lesions. A total body skin examination was performed on every patient. Nevi exhibiting morphological changes such as asymmetry, irregular borderes and color variation were given the clinical diagnosis of dysplastic or atypical nevus. 
Table 1: Age distribution in the total cohort and in the criterion 1 and criterion 2 groups.

\begin{tabular}{|l|l|l|l|l|l|l|l|l|l|l|}
\hline Age & $0-10$ & $11-20$ & $21-30$ & $31-40$ & $41-50$ & $51-60$ & $61-70$ & $71-80$ & $81-90$ & Total \\
\hline Total & 3 & 9 & 11 & 38 & 16 & 30 & 29 & 11 & 1 & 148 \\
\hline Crit 1 & 3 & 8 & 9 & 20 & 13 & 14 & 11 & 6 & 0 & 84 \\
\hline Crit 2 & 0 & 0 & 0 & 0 & 0 & 16 & 18 & 5 & 1 & 40 \\
\hline
\end{tabular}

\section{RESULTS}

A total number of 148 patients (M:62, F:86) was sceened during the 2 days. The age distribution is shown in Table 1. The screening program appeared to be more attractive with increasing age.

The vast majority of the screened individuals belonged to light skin and photosensitive groups (phototypes 1: 10,8\%, 2: 53,4\%, 3: 34,5\%, 4: 1,4\% respectively).

A total of $24 / 148(17,6 \%)$ of the screened patients had used self-tanning UV-delivering devices either at home or in a sun parlour. Of these individuals 8,3\% had 1 session per year, 33,3\% had 5 sessions per year, $33,3 \%$ had 10 sessions per year, and $25 \%$ had more than 10 sessions per year

The percentage of patients recalling sunburns during infancy reached $81,8 \%$ (45,2\% rarely, $36,5 \%$ frequent1y). Data were similar in the 2 screening centers.

The total number of patients meeting the predefined selection criteria was $124 / 148(83,7 \%)$ (Table 1$)$. The adherence to the selection criterion 1 (patients presenting over 30 nevi) was higher compared to criterion 2 (patients over the age of 50 presenting recent skin changes in the head and neck area) (56,7\% versus $27 \%)$. No differences were yielded between the 2 screening centers. Of the 84 patients meeting criterion 1 , the age distribution is presented in table 1 . The phototype distribution was the following; type 1: 12\%, 2: 67\%, 3: 33\%, 4: 0\% respectively). Sunburn was recalled in $89,1 \%$ (75 patients, $60 \%$ (40 patients) frequently, $40 \%$ rarely (35 patients)). Sunbed use was noted in 15 patients $(17,8 \%)(6,6 \%$ had 1 session per year, $20 \%$ had 5 sessions per year, $26,6 \%$ had 10 sessions per year, and $46,6 \%$ had more than 10 sessions per year).

Of the 40 patients responding to criterion 2, the age distribution is given in table 1 . The phototype distribution was the following; type 1: 2,5\%, 2: $30 \%, 3: 65 \%$, 4: $2,5 \%$ respectively). Sunburn was recalled in $85 \%$ (34 patients, 58,8\% (20 patients) frequently, $41,2 \%$ rarely (14 patients)). Sunbed use was noted in 9 patients $(22,5 \%)$ $(11,1 \%$ had 1 session per year, $11,1 \%$ had 5 sessions per year, 33,3\% had 10 sessions per year, and 44,4\% had more than 10 sessions per year).

The clinical and dermoscopic diagnoses (if applicable) are summarized in table 2 for the total cohort as well as the two predefined groups. Excision of the maligant lesions was adviced. Strict surveillance of atypical nevi and actinic keratosis was also adviced.

During the 2 months following the campaign, 5 histologically proven $\mathrm{MM}$ were detected by the participating dermatologists.

\section{DISCUSSION}

The global incidence of MM and skin carcinomas has steadily and rapidly increased over the past 2 decades (1-11). Skin carcinomas are seldom lethal, but, if advanced, can cause severe disfigurement and morbidity. Early detection and treatment of MM should reduce mortality rates, while early detection and treatment of skin carcinomas might prevent morbidity and to a lesser degree prevent mortality. These data underline the importance of early detection and therapy.

Skin cancer screening campaigns have proven to be successful in achieving public education on skin cancers and their risk factors (26-32). Indeed, increased public awareness regarding skin cancer probably represents the main impact of skin cancer screening programs (41).

The present targeted skin cancer screening campaign has achieved different goals. During the screening days, 4 cases of skin carcinomas were clinically diagnosed. In addition, during the following 2 months, 5 histologically proven cases of MM were detected by the participating dermatologists. This figure represents about $30 \%$ of the total number of MM detected yearly in this Belgian region. An increased number of consultations for pigmentary lesions was also experienced. Furthermore, the media campaign increased the population awareness of skin cancers, promoted effective sun protection and make known the dangers of excessive UV-exposures.

As preselection of at risk patients increases the efficacy of screening programs $(27,31,32)$, two patient 
Table 2: Clinical and dermoscopic diagnosis (if applicable) in the entire group as well as in the groups meeting criterion 1 and 2 . As one patient may have several diagnosis, only the number of diagnoses is given.

\begin{tabular}{|l|c|c|c|}
\hline Diagnosis & Total & Crit 1 & Crit 2 \\
\hline $\begin{array}{l}\text { Melanocytic naevus (intradermal, } \\
\text { compound, and junctional) }\end{array}$ & 57 & 39 & 9 \\
\hline Congenital naevus & 3 & 2 & 0 \\
\hline Becker's naevus & 1 & 1 & 0 \\
\hline Lentigines & 17 & 1 & 5 \\
\hline Naevus spilus & 3 & 2 & 1 \\
\hline Sutton (halo) naevus & 2 & 2 & 0 \\
\hline Dysplastic naevus & 23 & 19 & 3 \\
\hline $\begin{array}{l}\text { Seborrheic keratosis (and pigmented } \\
\text { seborrheic keratosis) }\end{array}$ & 25 & 12 & 10 \\
\hline Dermatofibroma & 2 & 0 & 0 \\
\hline Fibrous papule of the face & 1 & 0 & 0 \\
\hline Actinic keratosis & 12 & 1 & 9 \\
\hline Superficial BCC & 1 & 0 & 1 \\
\hline Nodular BCC & 3 & 0 & 3 \\
\hline SCC & 0 & 0 & 0 \\
\hline MM & 0 & 0 & 0 \\
\hline
\end{tabular}

populations were targeted via the media. A total number of $83,7 \%$ of the screened patients met the predetermined criteria. The criterion « 30 or more moles » achieved significantly higher scores compared to the criterion « recent skin changes ». This could be partially related to the Melanoma Monday and Euromelanoma campaigns focussing particularly on MM (25). This figure may also be partially due to the centralised appointment office enabling a preselection. The most frequently encountered patient misjudgement were multiple seborrheic keratoses and lentiginosis. When the criterion 1 group is considered, it is noted that sunbed use is more frequent and more often compared to the entire screened patient group. The diagnosis of melanocytic nevi as well as dysplastic nevi was effectively particularly high in group 1 compared to group 2. Furthermore, all the cases of skin cancer and the majority of cases of actinic keratosis were effectively diagnosed in criterion group 2. Although the total cohort is too limited to achieve significative statistics, the results demonstrate the interest of preselection.

The simultaneous presence of 4 dermatologists was useful for opinion exchanges about puzzling lesions. In particular, diagnosing dysplastic nevus was often subject to second opinion.
In conclusion, the skin cancer screening campaign performed in the German-speaking Community of Belgium led to the diagnosis of 4 cases of skin carcinomas during the screening days. It probably invited the 5 patients with $\mathrm{MM}$ to consult during the 2 following months. In addition, patient awareness was increased on skin cancer issues, prevention methods as well as on the long-term dangers of UV-exposure. This probably represents the main positive impact of the campaign.

\section{LITERATURE}

1. Rampen FH, Neumann HA, Kiemeney LA. Fundamentals of skin cancer/melanoma screening campaigns. Clin Exp Dermatol $1992 ; 17: 307-12$.

2. Rampen FH, Casparie-van Velsen JI, van Huystee BE, Kiemeney LA, Schouten LJ. False-negative findings in skin cancer and melanoma screening. J Am Acad Dermatol $1995 ; 33: 59-63$.

3. Miller DL, Weinstock MA. Nonmelanoma skin cancer in the United States: incidence. J Am Acad Dermatol 1994 ;30 :7748.

4. Rhodes AR. Public education and cancer of the skin. What do people need to know about melanoma and nonmelanoma skin cancer? Cancer 1995 ;75(2 Suppl):613-36.

5. Marks R, Motley RJ. Skin cancer. Recognition and treatment.Drugs 1995 ;50:48-61.

6. Nikkels-Tassoudji N, Nikkels AF, Piérard GE. Une tumeur préauriculaire. Rev Med Liege 2002;57:65-6.

7. Piérard-Franchimont C, Uhoda I, Piérard GE. Cutaneous cancers in the Mosan region and Ardennes of Belgium. Dermatology 1999;198:187-91.

8. Piérard-Franchimont C, Arrese JE, Cornil F, Damseaux M, Darcis JM, Deleixhe-Mauhin F, Delvoye P, Fraiture AL, Gerardy-Goffin F, Giet-Lesuisse M, Goffin V, Henry F, Hermanne-Wolf P, Hermanns JF, Hermanns-Le T, Heymans O, Letawe C, Nikkels AF, Nikkels-Tassoudji N, Perrier d'Auterive-Willemaers V, Rakic L, Soyeur-Broux M, Sproten G, Uhoda I, Piérard GE. Les mélanomes cutanés, un spectre de cancers émergents chez la femme en région wallonne. Rev Med Liège 1999 ;54:495-9.

9. Piérard GE, Piérard-Franchimont C, Arrese JE, Cornil F, Darcis JM, Deleixhe-Mauhin F, Delvoye P, Gerardy-Goffin F, GietLesuisse M, Goffin V, Henry F, Hermanns JF, Hermanns-Le T, Marchoul JC, Martalo O, Nikkels AF, Nikkels-Tassoudji N, Paquet P, Soyeur-Broux M, Piérard-Franchimont C. Relativité de la prise en charge des cancers cutanés. Plaidoyer pour la synergie entre le médecin généraliste et le dermatologueoncologue. Rev Med Liège 2000 ;55 :247-52.

10. Wolfe JT. The role of screening in the management of skin cancer. Curr Opin Oncol $1999 ; 11: 123-8$.

11. Desmond RA, Soong SJ. Epidemiology of malignant melanoma. Surg Clin North Am 2003 ; 83:1-29.

12. Fleming ID, Amonette R, Monaghan T, Fleming MD. Principles of management of basal and squamous cell carcinoma of the skin. Cancer $1995 ; 75$ :Suppl 699-704.

13. Kuijpers DI, Thissen MR, Neumann MH. Basal cell carcinoma: 
treatment options and prognosis, a scientific approach to a common malignancy. Am J Clin Dermatol 2002 ;3:247-59.

14. Nikkels AF, Piérard GE. Une tumeur du cuir chevelu révélatrice d'une naevomatose basocellulaire. Rev Med Liège 2002; 57: 185-6.

15. Arrese Estrada J, Greimers R, Ben Mosbah T, Fazaa B, PierardFranchimont C, Pierard GE. Epithélioma spinocellulaire. Rev Med Liege 1991 ; 46:633-40.

16. Rowe DE, Carroll RJ, Day CL Jr. Prognostic factors for local recurrence, metastasis, and survival rates in squamous cell carcinoma of the skin, ear,and lip: implications for treatment modality selection. J Am Acad Dermatol 1992 ;26 :976-90.

17. Gallagher RP, Hill GB, Bajdik CD, et al. Sunlight exposure, pigmentation factors, and risk of nonmelanocytic skin cancer. II. Squamous cell carcinoma. Arch Dermatol 1995 ;131 :1649.

18. Alam M, Ratner D. Cutaneous squamous-cell carcinoma. New Engl J Med 2001 ; 344 : 975-83.

19. Lamote J. Primary management of cutaneous melanoma: excision and sentinel node biopsy. Acta Chir Belg 2002 ;102: 147-51.

20. Lens MB, Dawes M, Newton-Bishop JA, Goodacre T. Tumour thickness as a predictor of occult lymph node metastases in patients with stage I and II melanoma undergoing sentinel lymph node biopsy. Br J Surg 2002 ;89:1223-7.

21. Brandt TP. Skin cancer screening. Med Clin North Am 1996 ;8: 99-114.

22. Girgis A, Clarke P, Burton RC, Sanson-Fisher RW. Screening for melanoma by primary health care physicians: a costeffectiveness analysis. J Med Screening 1996 ; 3 :47-53.

23. Hill D, Marks R, Boulter J. Public health approaches to skin cancer control. Australasian J Dermatol 1997 ;38 S1 :73-8.

24. Sladden MJ, Ward JE, Del Mar CB, Lowe JB. Skin cancer screening by Australian family physicians: variation with physician beliefs and geographic locality. Am J Preventiv Med $1999 ; 17: 142-6$

25. Vandaele MM, Richert B, Van der Endt JD, et al. Melanoma screening: results of the first one-day campaign in Belgium (Melanoma Monday'). J Eur Acad Dermatol 2000 ;14 :470-2.

26. Friedman LC, Bruce S, Webb JA, Weinberg AD, Cooper HP. Skin self-examination in a population at increased risk for skin cancer. Am J Preventiv Med 1993 ; 9:359-64.

27. Muglia JJ, Pesce K, McDonald CJ. Skin cancer screening: A growing need. Surg Oncol Clin North Am 1999 ; 8:735-45.

28. Geller AC. Screening for melanoma. Dermatologic Clinics $2002 ; 20: 629-40$.
29. Geller AC. Zhang Z. Sober AJ et al. The first 15 years of the American Academy of Dermatology skin cancer screening programs: 1985-1999. J Am Acad Dermatol 2003 ;48:34-41.

30. Geller AC, Sober AJ, Zhang Z, et al. Strategies for improving melanoma education and screening for men age $>$ or $=50$ years: findings from the American Academy of Dermatological National Skin Cancer Sreening Program. Cancer 2002; 95: 1554-61.

31. Cummings SR,Tripp MK, Herrmann NB. Approaches to the prevention and control of skin cancer. Canc Metast Reviews 1997 ;16:309-27.

32. MacKie RM, Bray CA, Leman JA. Effect of public education aimed at early diagnosis of malignant melanoma: cohort comparison study. BMJ 2003 ;326:367.

33. Argenziano G, Soyer HP. Dermoscopy of pigmented skin lesions--a valuable tool for early diagnosis of melanoma. Lancet Oncology 2001:443-9.

34. Stolz W, Semmelmayer U, Johow K, Burgdorf WH. Principles of dermatoscopy of pigmented skin lesions. Semin Cut Med Surg $2003 ; 22: 9-20$.

35. de Rooij MJ, Rampen FH, Schouten LJ. Neumann HA. Skin cancer screening focusing on melanoma yields more selective attendance. Arch Dermatol $1995 ; 131$ :422-5.

36. Weinstock MA. Point-counterpoint. Mass population skin cancer screening can be worthwhile--(if it's done right). J Cut Med Surg $1998 ; 2: 129-32$.

37. Rampen RH. Point-counterpoint. Mass population skin cancer screening is not worthwhile. J Cut Med Surg 1998 ; 2 :128-9.

38. Helfand M, Mahon SM, Eden KB, Frame PS, Orleans CT. Screening for skin cancer. Am J Preventiv Med 2001; $20(3$ Suppl):47-58.

39. Swetter SM, Waddell BL, Vazquez MD, Khosravi VS. Increased effectiveness of targeted skin cancer screening in the Veterans Affairs population of Northern California. Preventive Medicine 2003 ; 36:164-71.

40. Berwick M, Fine JA, Bolognia JL. Sun exposure and sunscreen use following a community skin cancer screening. Prevent Med $1992 ; 21: 302-10$

41. Carli P, De Giorgi V, Giannotti B, et al. Skin cancer day in Italy: method of referral to open access clinics and tumor prevalence in the examined population. Eur J Dermatol 2003 ; 13:76-9. 